\section{Virologia ambiental e saneamento no Brasil: uma revisão narrativa}

\author{
Environmental virology and sanitation in Brazil: \\ a narrative review
}

\author{
Virología ambiental y saneamiento en Brasil: \\ una revisión narrativa
}

\author{
1 Instituto Oswaldo Cruz, \\ Fundação Oswaldo Cruz, \\ Rio de Janeiro, Brasil. \\ Correspondência \\ T. Prado \\ Instituto Oswaldo Cruz, \\ Fundação Oswaldo Cruz. \\ Av. Brasil 4365, Rio de \\ Janeiro, RJ 21040-360, Brasil. \\ tprado@ioc.fiocruz.br
}

\begin{abstract}
Sanitation services play a critical role in controlling transmission of numerous waterborne pathogens, especially viruses that cause acute gastroenteritis and hepatitis. The viral agents with the greatest public health impact are hepatitis A virus, rotaviruses and noroviruses, adenoviruses, and enteroviruses, contaminating many Brazilian aquatic ecosystems. Heavy circulation of viruses in the environment has been related to inadequate local sanitary conditions, including incomplete coverage of services or inefficacy of conventional technologies in eliminating or reducing the viral load in water or sewage. This study reviews the relations between virology, health, and sanitation, emphasizing the epidemiology of waterborne viral infections and their public health impact.
\end{abstract}

Virology; Basic Sanitation; Waterborne Diseases
Tatiana Prado 1

Marize Pereira Miagostovich 1

\section{Resumen}

Os serviços de saneamento básico têm papel fundamental no controle da transmissão de diversos agentes patogênicos de veiculação hídrica, especialmente vírus responsáveis por causar gastroenterites agudas e hepatites. Entre os agentes virais de maior impacto para a saúde pública, podem ser destacados os vírus das hepatites A, os rotavírus e norovírus, adenovírus e enterovírus, os quais são responsáveis pela contaminação de diversos ecossistemas aquáticos brasileiros. A alta circulação de vírus no ambiente vem sendo relacionada às condições sanitárias inadequadas das comunidades, incluindo a falta na cobertura de serviços ou ineficácia de tecnologias convencionais na eliminação ou redução da carga viral presente na água ou no esgoto. Este estudo aborda uma revisão das relações entre virologia, saúde e saneamento, enfatizando a epidemiologia das infecções virais de transmissão hídrica e o impacto na saúde pública.

Virologia; Saneamento Básico; Doenças

Transmitidas pela Água 


\section{Introdução}

A virologia ambiental compreende um extenso campo de pesquisa, possuindo interface com políticas públicas específicas, tais como: saneamento, recursos hídricos, gerenciamento costeiro, vigilância sanitária e epidemiológica 1 .

Os vírus entéricos ou de disseminação entérica são frequentemente alvo de investigações no ambiente e pertencem a diversas famílias e gêneros, estando associados a diferentes quadros de doenças infecciosas (Tabela 1). O termo "vírus entéricos" representa todos os grupos virais presentes no trato gastrointestinal humano e que, após transmissão fecal-oral, podem causar infecções em indivíduos susceptíveis. São vírus de simetria icosaédrica, não envelopados e altamente resistentes às condições desfavoráveis do meio ambiente 2 .

Os norovírus (NoV) constituem os principais agentes virais entéricos responsáveis pelos surtos de gastroenterite de veiculação hídrica no mundo, seguidos pelos adenovírus (AdV), echovírus e vírus da hepatite $\mathrm{A}(\mathrm{HAV}){ }^{3}$. O rotavírus do grupo A (RV-A), considerado o principal responsável pela gastroenterite infantil aguda, também tem sido relacionado a diversos surtos de gastroenterite de veiculação hídrica 1,2 .

Pacientes com gastroenterites ou hepatites virais excretam de $10^{5}$ a $10^{13}$ partículas de vírus por grama de fezes ${ }^{2,4} \mathrm{e}$, portanto, esses patógenos estão presentes em altas concentrações em águas residuárias, principalmente em regiões endêmicas ou quando ocorrem surtos na comunidade 2 .

O saneamento básico tem papel fundamental no controle da disseminação desses vírus no ambiente, diminuindo os riscos de transmissão. Diversos estudos têm demonstrado as correlações entre a falta de saneamento, incluindo acesso à água potável e esgotamento sanitário, com o aumento das taxas de morbidade e mortalidade por doenças infecciosas, sobretudo a diarreia infantil 5,6,7,8,9.

O Brasil ainda enfrenta um problema histórico em termos de distribuição e acesso aos serviços básicos de saneamento, principalmente esgotamento sanitário 10,11,12. As desigualdades no acesso aos serviços de saneamento básico causam impacto negativo à saúde pública, principalmente nas populações de baixa renda ou vulneráveis que vivem na periferia das grandes cidades 6,8,13,14.

A gestão integrada em saúde, incluindo a universalização do acesso aos serviços básicos de saneamento e a melhoria das condições de salubridade ambiental, é fundamental para o desenvolvimento econômico e social. Os determi- nantes socioambientais que afetam a qualidade do meio ambiente e a epidemiologia das infecções virais serão discutidos no texto, recorrendo aos dados de pesquisas recentes realizadas no país e ao impacto desses estudos na orientação de políticas públicas de prevenção e promoção da saúde.

\section{Tratamento de água e esgoto no Brasil}

As doenças infecciosas de transmissão hídrica, notadamente as doenças diarreicas e as hepatites virais, ainda representam um sério problema de saúde pública, afetando, principalmente, crianças dos países em desenvolvimento ${ }^{15}$. No Brasil, segundo estimativa da Organização Mundial da Saúde (OMS), os fatores ambientais são responsáveis por $19 \%$ do total de doenças que afetam o país e por 5,4\% do acometimento por doenças diarreicas 16 .

Embora sejam intrínsecas as relações do papel do saneamento adequado na melhoria da qualidade de vida e da saúde da população, o Brasil ainda apresenta um déficit histórico em termos de cobertura de serviços básicos de saneamento. Nos últimos anos, ocorreram avanços significativos dos investimentos em saneamento, sobretudo na cobertura da população aos serviços de água potável, mas o mesmo não foi verificado para a oferta de serviços de esgotamento sanitário (Tabela 2) 12. No Brasil, apenas 37,9\% dos esgotos produzidos passam por algum processo de tratamento antes de serem descartados no ambiente, revelando o crônico problema da falta de saneamento básico no país.

É importante enfatizar que, mesmo nas regiões com melhores índices de cobertura de serviços de saneamento, ainda persistem grandes diferenciais intrarregionais e intraurbanos 8 . As regiões Norte e Nordeste do país são as que mais sofrem com a falta de serviços de esgotamento sanitário adequado e também as que apresentam as maiores taxas de mortalidade por doenças diarreicas agudas em menores de cinco anos de idade (Departamento de Informática do SUS. Sistema de Informações de Mortalidade. Mortalidade Proporcional por Doença Diarreica Aguda em Menores de 5 Anos de Idade. http://tabnet. datasus.gov.br/cgi/tabcgi.exe?idb2011/c06.def, acessado em 20/Fev/2013). Há uma forte correlação entre o acesso à cobertura e os níveis de renda da população. Enquanto nos domicílios com rendimento médio mensal de mais de cinco salários mínimos os índices de cobertura chegam a $75,6 \%$, nos domicílios com renda média mensal de até $1 / 2$ salário mínimo, os índices de cobertura são de $41 \% 17$. 
Vírus detectados em ecossistemas aquáticos e doenças associadas.

\begin{tabular}{|c|c|c|}
\hline Gênero (genoma) & Nome popular & Doenças associadas \\
\hline \multirow[t]{4}{*}{ Enterovirus (RNAfs) } & Poliovírus (PV) & Paralisia, meningite, febre \\
\hline & Coxsackievírus A/ & Meningite, febre, doença respiratória, doença das mãos, pés e boca, \\
\hline & Coxsackievírus B & miocardites, anomalias do coração, diabetes \\
\hline & Echovírus & Meningite, febre, doença respiratória, gastroenterite \\
\hline Hepatovirus (RNAfs) & Vírus da hepatite $A(H A V)$ & Hepatite \\
\hline Rotavirus (RNAdf segmentado) & Rotavírus (RV) & Gastroenterite \\
\hline Norovirus (RNAfs) & Norovírus humano (HuNoV) & Gastroenterite \\
\hline Hepevirus (RNAfs) & Vírus da hepatite E (HEV) & Hepatite \\
\hline Mamastrovirus (RNAfs) & Astrovírus humano (HAsTV) & Gastroenterite \\
\hline Mastadenovirus (DNAdf) & Adenovírus humano (HAdV) & Gastroenterite, doença respiratória, conjuntivite \\
\hline Polyomavirus (DNAdf) & Poliomavírus humano (JCPyV) & Leucoencefalopatia multifocal progressiva, doenças do trato urinário \\
\hline Alphatorquevirus (DNAfs) & Torque teno vírus (TTV) & Desconhecida/Hepatite \\
\hline Kobuvirus (RNAfs) & Klasse vírus & Gastroenterite \\
\hline
\end{tabular}

df: dupla fita; fs: fita simples.

Fonte: modificado de Bosch et al. 2 .

Tabela 2

Níveis médios de atendimento de água e esgoto dos prestadores de serviços participantes do Sistema Nacional de Informações sobre Saneamento (SNIS). Brasil e regiões, 2010.

\begin{tabular}{|c|c|c|c|c|c|}
\hline \multirow[t]{3}{*}{ Região } & \multicolumn{4}{|c|}{ Índice de atendimento com rede (\%) } & \multirow{3}{*}{$\begin{array}{c}\text { Tratamento de } \\
\text { esgoto gerado } \\
\text { (\%) }\end{array}$} \\
\hline & \multicolumn{2}{|c|}{ Água } & \multicolumn{2}{|c|}{ Coleta de esgoto } & \\
\hline & Total & Urbano & Total & Urbano & \\
\hline Norte & 57,5 & 71,8 & 8,1 & 10,0 & 22,4 \\
\hline Nordeste & 68,1 & 87,1 & 19,6 & 26,1 & 32,0 \\
\hline Sudeste & 91,3 & 96,6 & 71,8 & 76,9 & 40,8 \\
\hline Sul & 84,9 & 96,0 & 34,3 & 39,9 & 33,4 \\
\hline Centro-oeste & 86,2 & 95,3 & 46,0 & 50,5 & 43,1 \\
\hline Brasil & 81,1 & 92,5 & 46,2 & 53,5 & 37,9 \\
\hline
\end{tabular}

Fonte: Sistema Nacional de Informações sobre Saneamento 12.

A falta ou ineficácia dos serviços de esgotamento sanitário contribui para agravar os níveis de degradação dos ecossistemas aquáticos e a disseminação viral no ambiente. Vírus entéricos representam riscos potenciais à saúde quando estão presentes nesses ecossistemas 2, principalmente por apresentarem baixa dose infecciosa (1 a 100 partículas virais podem causar infecção em indivíduos susceptíveis quando da ingestão ou contato com a água contaminada) 18 .

Tecnologias convencionais baseadas no tratamento biológico de esgotos removem somente cerca de 20 a $80 \%$ dos vírus entéricos presentes no esgoto bruto, permitindo que uma carga viral significativa seja disseminada nos corpos hídricos 19. Cargas virais da ordem de 102-108 cópias de genoma por litro de esgoto tratado foram observadas em diversas estações de tratamento de esgoto (ETEs) no país 20,21,22,23,24,25,26. Alguns desses estudos demonstram que mesmo a cloração, que tem sido o processo mais utilizado no Brasil para promover a desinfecção final de esgotos, não tem sido efetiva na remoção viral 23,27. A cloração ainda é a tecnologia mais barata e não necessita de manutenção ou treinamento especializado para a aplicação. Dados 
mais recentes demonstram que os vírus seriam mais efetivamente removidos pelos sistemas com níveis de tratamento mais avançados, tais como biorreatores de membrana (MBRs) 27,28 ou precipitação por coagulação 29 . Outros processos de desinfecção como ozonização ou luz ultravioleta (UV) também são descritos como mais efetivos na remoção de vírus em ETAs 27,30,31.

A contaminação crescente dos recursos hídricos gera um ônus para o sistema público de abastecimento de água, uma vez que tratamentos cada vez mais sofisticados devem ser utilizados para promover a potabilidade da água Quanto maior o nível de poluição das águas utilizadas para abastecimento, menor a eficiência de remoção viral, que está relacionada com a presença de materiais particulados ou sólidos em suspensão na água 18. Processos de desinfecção, como a UV, frequentemente são necessários para a completa inativação viral 18, podendo ser utilizados em ETAs. Em nível individual, a utilização de filtros caseiros auxilia no processo de purificação da água, embora a eficiência desses filtros na remoção viral dependa do tipo de meio filtrante utilizado, dado que os vírus são partículas com tamanhos de 20-300nm de diâmetro.

A falta de incentivo para o estabelecimento de tecnologias mais avançadas se deve aos custos de investimentos necessários para a expansão das redes de tratamento, dada a necessidade de maior aporte de recursos para a implantação, operação e manutenção dos sistemas. No entanto, escolhas baseadas em critérios econômicofinanceiros podem contradizer o interesse público em termos de bem-estar e saúde pública. As dificuldades técnicas e financeiras não deveriam representar barreiras, mas incentivos para o desenvolvimento mais equitativo e sustentável do meio ambiente. Enquanto os serviços de saneamento básico não se universalizarem e as ETEs de tratamento de esgotos convencionais não eliminarem os vírus dos efluentes tratados, a disseminação viral no ambiente agravará o problema da falta de qualidade sanitária das águas, implicando em riscos para a saúde pública.

\section{Disseminação viral em ecossistemas aquáticos brasileiros}

\section{RV}

Os RV são descritos dentro do gênero Rotavirus que inclui, pelo menos, sete grupos (A-G) e que podem ser distinguidos com base nas suas relações antigênicas e nos padrões de migração dos segmentos de RNA dupla fita em eletroforese em gel de poliacrilamida ${ }^{32}$. Os RV-A são os princi- pais agentes responsáveis pelas gastroenterites que acometem crianças menores de cinco anos de idade em várias regiões do mundo 33,34. São classificados em sorotipos ou genótipos G (Glicoproteína) e $\mathrm{P}$ (sensível à protease), sendo, atualmente, reconhecidos 27 genótipos G e 35 P 33.

Em março de 2006, uma vacina de RV-A atenuado G1P[8] (Rotarix, GlaxoSmithKline, Rixensart, Bélgica) foi introduzida no calendário nacional de imunizações 32,35 . Os efeitos positivos da vacinação contra RV-A sobre a redução das taxas de morbidade e mortalidade no Brasil e em países em desenvolvimento têm sido observados 33,35, embora alguns estudos apontem para a complexidade dos padrões de evolução desses vírus após o período de pós-vacinação, no qual alguns genótipos de RV-A estariam emergindo ou reemergindo $36,37,38$. A emergência de genótipos não usuais pode estar associada a flutuações genotípicas naturais, ocorrendo até mesmo em países que não possuem programas de vacinação universal 32 .

O monitoramento ambiental tem sido uma ferramenta útil para avaliar o impacto do programa de vacinação na circulação de RV-A em alguns países 20. A maior frequência de RV-A vem sendo detectada em águas de rios, esgotos, lagoas urbanas e córregos poluídos em cidades com grande adensamento populacional, como São Paulo e Rio de Janeiro, com frequências de detecção variando de 20 a 100\% 20,23,39,40,41,42. Recentemente, o RV-A foi detectado em $100 \%$ de amostras de esgoto bruto e em $71 \%$ em esgoto tratado de uma ETE no Rio de Janeiro 20, superando as taxas de detecção para outros vírus de disseminação entérica nos afluentes dessa mesma ETE 24. Neste estudo, foi observada a predominância dos genótipos G2 e P[4], sem a ocorrência de cepas de origem vacinal 20 . Além disso, não foi encontrada uma variação sazonal de RV-A detectado ao longo de um ano nas águas residuais do Estado do Rio de Janeiro ${ }^{20}$, ao contrário de outros estudos internacionais demonstrando que a ocorrência de RV-A é predominante nos meses de inverno 29. A ausência de um inverno rigoroso ou de grandes variações na amplitude da temperatura ao longo do ano no Rio de Janeiro poderia justificar esses resultados.

Em regiões rurais ou próximas a florestas nos rios da Região Amazônica, a presença de RV-A foi predominante sobre os outros vírus gastroentéricos 43 . Entretanto, a frequência de detecção de RV-A foi menor na área rural (28\%) comparada aos resultados obtidos na área urbana (62\%) daquela região 43 .

A predominância dos RV-A em relação a outros vírus de disseminação entérica também foi observada nas águas da Lagoa Rodrigo de Freitas 
(Rio de Janeiro), com $24 \%$ de positividade do total de amostras pesquisadas e em 50\% de amostras que estavam dentro dos padrões de balneabilidade, de acordo com a análise de coliformes fecais, demonstrando que padrões de monitoramento bacterianos não são adequados para avaliar o nível de contaminação viral em amostras ambientais 40

Uma questão importante na epidemiologia das infecções por RV refere-se ao potencial de transmissão zoonótica. A transmissão interespécies de RV humanos e suínos foi apontada em um estudo conduzido em Belém (Pará), com a detecção de segmentos do gene VP6 pertencentes à RV-C de suínos causando gastroenterite em crianças que viviam em contato próximo a esses animais naquela região 44 .

\section{NoV}

Os NoV pertencem ao gênero Norovirus e à família Caliciviridae e são transmitidos principalmente pelo contato pessoa a pessoa, por água e alimentos contaminados, sendo os principais responsáveis por surtos de gastroenterite aguda recorrentes em hospitais, escolas, asilos, restaurantes e cruzeiros de viagens, infectando e causando doenças igualmente em crianças e adultos 3,45 .

Os NoV são classificados dentro de cinco genogrupos (GI-GV), três dos quais representam vírus que infectam humanos (GI, GII e GIV) e dois que infectam bovinos e murinos (GIII e GV, respectivamente) 45 . Os genogrupos são subdivididos em 35 genótipos (8 GI, 21 GII, 3 GIII, 2 GIV e 1 GV), e a variabilidade genética é alta quando comparada a gêneros de outras famílias de vírus com genoma de RNA 46. Os NoV GII.4 são prevalentes em surtos de gastroenterite ao redor do mundo, incluindo o Brasil 47,48,49. Estudos têm demonstrado que os NoV GII.4 acumulam mutações ao longo do tempo na sequência nucleotídica do gene que codifica a proteína VP1, o qual permite evasão da imunidade na população humana 47.

Os NoV são amplamente disseminados em diversos ecossistemas aquáticos brasileiros $21,23,24,40,43,50$, embora, em geral, tenham sido detectados em menores taxas quando comparados aos RV-A em águas residuárias do Rio de Janeiro (15 a $45 \%$ de positividade contra 20 a $100 \%$ para RV-A) 23,24, na Lagoa Rodrigo de Freitas (18\% de positividade contra $24 \%$ de RV-A) 40 e em rios da Bacia Amazônica $(5,8 \%$ de positividade contra 44\% de RV-A) 43.

As mais altas frequências de detecção de NoV vêm sendo detectadas em águas residuárias urbanas e hospitalares da cidade do Rio de Janeiro, com predominância do genótipo GII.4 21,23,24. A prevalência de NoV GII também foi observada em diversos ecossistemas aquáticos de Florianópolis (Santa Catarina), com predominância do GII.4 e do GII.2 50. Os resultados estão de acordo com outros estudos que verificaram a prevalência do genótipo GII.4 em amostras clínicas de diversas regiões brasileiras 48,49 , incluindo variantes desse genótipo que estão associadas a diversos surtos de gastroenterite provocados por NoV mundialmente 47,49. No entanto, o perfil epidemiológico pode variar conforme a região. Mais recentemente, NoV GI foi prevalente sobre o GII em amostras de águas costeiras analisadas na Região Sul (NoV GI 7,5\%; NoV GII 4,5\%) 51 .

Melhorias das condições de saneamento básico, assim como práticas de higiene adequadas constituem medidas preventivas importantes contra infecções por esses patógenos 45 , principalmente pela ausência de tratamento específico ou vacina disponível comercialmente 45 .

\section{HAV}

O HAV pertence à família Picornaviridae e é transmitido primariamente pela rota fecal-oral, diretamente de pessoa a pessoa ou por água e alimentos contaminados. Embora a vacinação seja uma medida eficaz na prevenção contra as infecções por HAV, a prevalência da infecção está associada às condições sanitárias e socioeconômicas das comunidades, sendo a hepatite A endêmica na América Latina 13,14,52.

Mesmo com o progressivo declínio das taxas de mortalidade e morbidade por infecção do HAV no Brasil, 51.756 casos foram notificados no período de 2007 a 2013, segundo dados do Sistema de Informação de Agravos de Notificação (SINAN) do Ministério da Saúde (Hepatites Virais. http://dtr2004.saude.gov.br/sinanweb/tabnet/ tabnet?sinannet/hepatitesvirais/bases/hepabr net.def, acessado em 10/Fev/2014). No ambiente, o HAV tem sido verificado em grandes proporções em ecossistemas de regiões com cobertura de saneamento inadequado, como rios da Bacia Amazônica 53 e em lagoas e águas residuárias de grandes cidades urbanas, principalmente Rio de Janeiro e São Paulo 22,23,54,55,56.

No caso da Região Sudeste, particularmente no Rio de Janeiro, a maior incidência de infecções por HAV ou taxas de prevalência anti-HAV ocorrem nas populações com menores níveis de renda ou acesso a serviços de saneamento básico inadequado 13,14. A falta de planejamento urbano e as condições climáticas também podem afetar os padrões epidemiológicos da doença na região. Foi observada uma maior incidência das infecções por HAV durante os meses mais quentes e 
chuvosos do ano ${ }^{57}$. Picos de concentrações de genomas de HAV também foram observados em esgotos do Rio de Janeiro nesse período 22,55, demonstrando que a abordagem ambiental é útil em estudos epidemiológicos.

No Sul do país, estudos conduzidos em Florianópolis (Santa Catarina) também demonstraram a contaminação por HAV e outros vírus gastroentéricos em águas superficiais, incluindo águas de recreação (lagoas e oceanos), assim como água potável não tratada, com taxas de detecção variando de 8 a 16\% 58. Entretanto, estudos de viabilidade das partículas virais não detectaram HAV com potencial infeccioso, embora o potencial de infecciosidade tenha sido observado para os outros vírus analisados, como RV-A e HAdV 58 .

A problemática dessa contaminação aumenta devido à tradição da região de Santa Catarina no cultivo de bivalves filtradores, tais como ostras, mariscos e mexilhões, sendo a principal produtora nacional. Bivalves são moluscos filtradores que retêm e acumulam vírus presentes em águas contaminadas, de modo que o consumo cru desses alimentos tem sido responsável por um grande número de surtos de gastroenterites e hepatite em todo o mundo ${ }^{2}$. O HAV tem sido detectado em ostras (Crassostrea gigas) cultivadas em fazendas marinhas dessa região com frequências de 31 a $79 \% 59$.

Na Região Norte, onde apenas $22 \%$ dos esgotos coletados passam por algum tipo de tratamento, o percentual de detecção de HAV foi de 92\% em rios da Bacia Amazônica cujos afluentes se situam próximos a áreas de urbanização desordenada e sem planejamento 53 . As cargas virais observadas atingiram de 60 a 5.500 cópias de genoma por litro de água 53, demonstrando uma elevada quantidade de vírus disseminados nesse ambiente. É importante observar que essas taxas são superiores àquelas verificadas em águas superficiais das regiões Sul 58 e Sudeste 56 . Esses dados corroboram dados clínicos que demonstram uma maior incidência da infecção na região do Amazonas (93,8/100 mil habitantes) comparada à média brasileira (11,2/100 mil habitantes) 60 .

Além da vacinação, a melhoria no acesso aos serviços de saneamento básico poderia contribuir para diminuir os riscos de transmissão do $\mathrm{HAV}$, particularmente em regiões que ainda são altamente endêmicas.

\section{AdV}

Os AdV pertencem à família Adenoviridae, no gênero Mastadenovirus, e são vírus não envelopados, com genoma de DNA dupla fita linear 61. Existem 51 sorotipos de AdV humanos que podem ser subdivididos em 6 espécies ou sub- grupos (A a F) com base na sorologia ou análise do genoma ${ }^{61}$. A espécie F (sorotipos 40 e 41) é responsável pela maioria dos casos de gastroenterite na população 61 .

Os AdV infectam uma grande diversidade de espécies, possuem tropismo variado, infectando vários sítios mucosos, incluindo o trato gastrointestinal, respiratório, geniturinário e superfícies oculares 61 e não apresentam sazonalidade 24,54,58,62. Adicionalmente, são mais resistentes do que outros vírus entéricos aos processos de desinfecção de água e esgoto 4.

A experiência brasileira tem demonstrado que os AdV estão amplamente disseminados no ecossistema aquático, incluindo a detecção de sorotipos gastroentéricos 40, 41 e respiratórios (sorotipo 2) 23,24,43,51,54.

Em águas residuárias e águas superficiais contaminadas, a frequência de detecção de AdV tem sido sempre superior a 55\% 23,24,43,51,54,58,62. Estudos que analisaram a infecciosidade das partículas de AdV demonstraram 50\% de viabilidade em água potável clorada 58 e 100\% em lodo de esgoto 62 . Recentemente, AdV infecciosos foram detectados em água clorada de abastecimento público no Estado de Santa Catarina, demonstrando a resistência dos mesmos ao processo de tratamento ${ }^{63}$. A detecção de AdV em ostras cultivadas na Região Sul do país também confirmou sua prevalência (100\%) em relação aos RV-A (8\%) 58.

Devido às altas frequências de detecção dos AdV em diversos tipos de ecossistemas aquáticos, a ausência de sazonalidade e a sua resistência aos processos de tratamento de água e esgoto, esses agentes têm sido considerados como bons indicadores para avaliar a contaminação viral humana no ambiente 63,64,65.

Outros vírus como JC polioma vírus [JCPyV]), colifagos e bacteriófagos também vêm sendo avaliados como potenciais indicadores de contaminação em diversas matrizes ambientais $24,62,64,65,66$. Entretanto, as facilidades na detecção dos AdV, que incluem seu isolamento em uma diversidade de cultivos celulares permitindo estudos de avaliação de risco, assim como sua estabilidade no ambiente, podem favorecer sua escolha 4,20,62,64,65, embora ainda não exista um consenso sobre um marcador ideal. Estudos nesse campo estão sendo realizados a fim de preencher as lacunas existentes sobre essa questão no país $24,54,58,62,66$, principalmente porque o uso de indicadores microbiológicos tradicionais utilizados para predizer a contaminação da água por poluição fecal humana (p.ex.: coliformes totais, fecais ou termotolerantes) é limitado para avaliar o nível de contaminação por vírus entéricos 56,64,65,67. 


\section{Outros vírus}

Em relação à pesquisa de enterovírus (EV), mais especificamente poliovírus PV (família Picornaviridae, gênero Enterovirus), é importante salientar que a vigilância ambiental tem sido preconizada pela OMS como uma importante ferramenta para avaliar a circulação de cepas vacinais e o possível surgimento de poliovírus derivados da vacina (VDPV) 68.

A erradicação da poliomielite no Brasil em 1989 foi resultante de um intenso programa de vacinação que utilizou a vacina oral de PV atenuado (VOP - cepa Sabin). Após a aplicação oral, os PV atenuados se replicam no trato gastrointestinal onde mutações e recombinações podem ocorrer 68. Como resultado, subpopulações contendo fenótipos virais alterados podem emergir, os quais podem incluir características de neurovirulência similares àquelas apresentadas pelos PV selvagens 68. Amostras que apresentam mais do que $1 \%$ de diferenças nucleotídicas quando comparadas à cepa Sabin correspondente são chamadas VDPV 71.

Um estudo conduzido com amostras de esgoto coletadas na cidade de São Paulo (1999-2001) demonstrou que nenhuma das amostras de PV vacinal isoladas era recombinante, e nenhum VDPV foi isolado durante o período do estudo, demonstrando que a vacina e as taxas de cobertura vacinais têm sido adequadas 69 .

Recentemente, EV também foram detectados em $100 \%$ de amostras de esgoto bruto e em $46 \%$ de esgoto tratado em diversas ETEs de São Paulo 70. No Rio de Janeiro, os EV foram recentemente pesquisados ao longo de um ano (20112012) em amostras de esgoto de uma grande ETE da cidade e foram detectados em $87 \%$ das amostras analisadas 71. Dos EV detectados, $29,6 \%$ foram caracterizados como PV vacinais ou Sabin-like, demonstrando a importância do monitoramento ambiental como instrumento útil de avaliação do Programa de Erradicação Global da Poliomielite da OMS 71.

A emergência ou reemergência de novos agentes virais, como os klasse vírus 72 e os Torque Teno Virus (TTV) 73, bem como daqueles com potencial de transmissão zoonótica, a exemplo do vírus da hepatite E (HEV) 74,75 e do circovírus suíno tipo 2 (PCV2) 26, tem sido avaliada no ambiente brasileiro.

O HEV vem sendo relacionado a diversos surtos de hepatite aguda causados pela ingestão de água e alimentos contaminados 74 . Infecta humanos e também outros animais, principalmente suínos, os quais são reservatórios desses vírus e podem ter papel importante na transmissão zoonótica 74,75 . A presença do HEV na bile de suínos e em amostras de efluentes de esgoto foi descrita recentemente no Brasil, alertando para o risco associado ao potencial de transmissão zoonótica caso não haja inspeção e cuidados sanitários adequados em abatedouros 74 .

\section{Virologia ambiental no Brasil}

No Brasil, a linha de pesquisa em virologia ambiental teve início na década de 1970 com o desenvolvimento de métodos para recuperar poliovírus tipo 1 a partir de grandes volumes de amostras de água 76. Nas décadas seguintes, a contaminação da água potável foi descrita como a possível causa de um surto de HAV ocorrido em um centro de pesquisas no Rio de Janeiro $77 \mathrm{e}$ foi demonstrada, pela primeira vez, a ocorrência de RV-A em córregos poluídos na cidade de São Paulo 39 .

Posteriormente, o estabelecimento de técnicas de biologia molecular, notadamente da reação em cadeia da polimerase (polymerase chain reaction - PCR), permitiu ampliar a análise para a detecção de uma variedade de grupos virais, principalmente aqueles não adaptados para a replicação viral em cultivos celulares, como é o caso dos NoV humanos 2,4,78. Com essa nova metodologia, os estudos em virologia ambiental foram intensificados, correlacionando a ocorrência de vírus em ecossistemas aquáticos com a falta de esgotamento sanitário adequado 40,41,43,50,51,53,56,58,73. Nesse contexto, a Secretaria de Vigilância em Saúde do Ministério da Saúde (SVS) estabeleceu o monitoramento das doenças de transmissão hídrica e alimentar. Atualmente, esforços têm sido realizados para o aprimoramento da coordenação dos serviços de Vigilância Epidemiológica dos Estados e municípios com os Laboratórios Centrais de Saúde Pública (LACENs) e a SVS 1.

Apesar da detecção de vírus em matrizes aquáticas ser recomendada como base laboratorial para a vigilância epidemiológica dessas infecções, não há, atualmente, um único método padronizado que seja adequado para qualquer tipo de água 1,78. A detecção de vírus em amostras ambientais representa um desafio, principalmente devido à grande variedade e complexidade de amostras. Adicionalmente, requer uma etapa prévia de concentração das amostras para redução do volume delas e a posterior utilização em análises moleculares. Essa etapa resulta na concentração de substâncias biológicas e químicas (ácidos húmicos, fúlvicos, gorduras, proteínas, polifenóis, metais pesados) presentes na amostra que interferem ou inibem as enzimas utilizadas nas metodologias de detecção 1,2,66,78. Por esse 
motivo, muitas vezes, os métodos utilizados para a detecção de vírus em diferentes matrizes ambientais geram resultados falso-negativos 2,78,79.

Metodologias analíticas mais acuradas, como a PCR em tempo real, vêm sendo estabelecidas para aumentar a eficiência de recuperação viral em diversas matrizes ambientais $2,42,66,78,79,80$. Adicionalmente, vírus com propriedades semelhantes aos vírus de interesse, de fácil manipulação e não detectados nos ambientes pesquisados, vêm sendo utilizados como controle interno do processo de recuperação viral nessas matrizes 79 . Bacteriófagos com genoma de RNA parecem promissores 42,79 , e a experiência brasileira demonstrou que resultados mais confiáveis podem ser obtidos mediante a utilização desses controles 20,42,66.

Ainda assim, tecnologias moleculares apresentam limitações, principalmente quando se trata de estudos que envolvem análise de risco, uma vez que essas metodologias não são capazes de avaliar o potencial infeccioso dos vírus detectados, por detectarem, somente, parte do seu material genético (DNA ou RNA) 78,80. Para superar esse obstáculo, algumas estratégias de detecção estão sendo avaliadas, incluindo a cultura de células integrada à PCR (integrated cell culture-ICC-PCR) 80.

Mesmo com os avanços metodológicos, até o momento, nenhum método atende aos critérios exigidos para a padronização, tais como simplicidade e rapidez de execução, reprodutibilidade, baixo custo e recuperação de uma grande variedade de tipos virais 1. Estudos de padronização e avaliação da eficiência de diferentes métodos de concentração associados aos métodos de detecção têm sido realizados com o objetivo de se disponibilizar um método de baixo custo que possa ser utilizado em monitoramentos para determinação da qualidade da água. Atualmente, a legislação brasileira responsável por controlar a qualidade da água para consumo humano (Portaria no 2.914 de 12 de dezembro de 2011 do Ministério da Saúde ${ }^{81}$ ) recomenda a pesquisa de vírus quando dados epidemiológicos apontarem a água como via de transmissão (Seção II e III, art. 11 e art. 12). No capítulo V (Padrão de Potabilidade), art. 29, a mesma portaria recomenda a inclusão do monitoramento de vírus entéricos no(s) ponto(s) de captação de água proveniente(s) de manancial(is) superficial(is) de abastecimento, com o objetivo de subsidiar estudos de avaliação de risco microbiológico, embora as investigações desses vírus em amostras ambientais ainda estejam restritas a laboratórios de pesquisa.

Além disso, os vírus não têm sido incluídos como padrões de monitoramento para avaliar a qualidade sanitária de efluentes produzidos em ETEs (resoluções CONAMA 357/2005 e 430/2011 82,83), resultando na carência de ações mais específicas destinadas ao controle da disseminação viral em corpos hídricos.

Importa destacar que as ações em virologia ambiental devem ser articuladas com políticas públicas específicas, sobretudo com aquelas formuladas para o setor de saneamento, saúde e meio ambiente (Tabela 3). Essa articulação poderá promover um conhecimento mais apurado da realidade sanitária, visando uma intervenção mais eficiente da comunidade científica e dos poderes públicos nos problemas socioambientais.

\section{Conclusões}

Embora seja difícil mensurar diretamente o impacto da contaminação ambiental na incidência e prevalência das doenças infecciosas nas comunidades, diversos trabalhos apontam que os riscos de saúde pública aumentam sob condições ambientais adversas, incluindo falta de acesso à água potável, esgotamento sanitário, coleta de resíduos sólidos e moradia adequada 5,6,7,8,9.

Pode-se constatar que o acesso ao saneamento básico, particularmente, esgotamento sanitário, ainda é bastante desigual no país e que esse está diretamente ligado à qualidade de vida da população. Dados sobre a distribuição e prevalência de grupos virais de importância médica no ambiente reforçam a importância do saneamento básico no controle das doenças virais de veiculação hídrica.

Nesse contexto, a virologia ambiental vem adquirindo um importante papel na construção de novos indicadores socioambientais. E esse papel se torna cada vez mais relevante na medida em que ela se constitui numa ferramenta útil de avaliação e controle da qualidade sanitária do ambiente e dos riscos à saúde da população. 
Políticas públicas e as interfaces com a virologia ambiental.

\begin{tabular}{|c|c|c|}
\hline Política & Objeto & Virologia ambiental \\
\hline Meio ambiente & $\begin{array}{c}\text { Preservação, melhoria e recuperação da } \\
\text { qualidade ambiental }\end{array}$ & Contribuir para a integração do planejamento urbano \\
\hline Recursos hídricos & $\begin{array}{c}\text { Assegurar a qualidade, a disponibilidade e o } \\
\text { uso racional dos recursos hídricos }\end{array}$ & $\begin{array}{l}\text { Definir parâmetros de qualidade da água; } \\
\text { Avaliação da dinâmica de transporte e sobrevivência viral em rios, } \\
\text { lagos, represas, mananciais de abastecimento de água etc. }\end{array}$ \\
\hline Gerenciamento costeiro & Utilização nacional dos recursos na zona costeira & $\begin{array}{l}\text { Definir parâmetros de qualidade de áreas recreacionais } \\
\text { (praias em cidades litorâneas) e fazendas marinhas } \\
\text { (produção de ostras, mariscos, mexilhões etc.) }\end{array}$ \\
\hline Saneamento básico & $\begin{array}{c}\text { Abastecimento de água potável, esgotamento } \\
\text { sanitário, manejo de resíduos sólidos e } \\
\text { águas pluviais urbanas }\end{array}$ & $\begin{array}{c}\text { Desenvolvimento e padronização de metodologias práticas, } \\
\text { com maior rapidez de execução, eficientes na detecção viral e } \\
\text { custo-efetivas; }\end{array}$ \\
\hline Vigilância sanitária & $\begin{array}{c}\text { Eliminar, diminuir ou prevenir riscos à saúde e de } \\
\text { intervir nos problemas sanitários decorrentes do } \\
\text { meio ambiente e alimentos }\end{array}$ & $\begin{array}{l}\text { Estabelecimento de indicadores virais apropriados para avaliar a } \\
\text { qualidade sanitária das águas e resíduos; } \\
\text { Capacitação de recursos humanos para realizar esse tipo de } \\
\text { diagnóstico }\end{array}$ \\
\hline Vigilância epidemiológica & $\begin{array}{l}\text { Conhecimento, detecção e prevenção de } \\
\text { mudanças nos fatores determinantes da saúde } \\
\text { individual ou coletiva com a finalidade de } \\
\text { recomendar e adotar as medidas de prevenção e } \\
\text { controle de doenças }\end{array}$ & $\begin{array}{c}\text { Monitorar a distribuição dos vírus presentes no ambiente } \\
\text { por meio da detecção e quantificação; } \\
\text { Avaliação de genótipos circulantes e estudos de } \\
\text { epidemiologia molecular; } \\
\text { Avaliação de riscos à saúde }\end{array}$ \\
\hline
\end{tabular}

Fonte: modificado de Machado 1

\section{Resumen}

El servicio de saneamiento posee un rol en el control de la transmisión de muchos patógenos transmitidos por el agua, especialmente aquellos virus responsables de causar gastroenteritis aguda y hepatitis. Entre los agentes virales de mayor impacto sobre la salud pública se pueden destacar los virus de la hepatitis A, rotavirus, norovirus, adenovirus y enterovirus, los cuales son responsables de la contaminación de diversos ecosistemas acuáticos brasileños. Una alta circulación del virus en el medio ambiente se relaciona con condiciones sanitarias inadecuadas de las comunidades, como la falta de cobertura de los servicios o la ineficacia de las tecnologías convencionales en eliminar la carga viral del agua. Esta revisión está enfocada en las relaciones entre la virología, la salud y el saneamiento, con énfasis en la epidemiología de las infecciones virales transmitidas por el agua y el impacto en la salud pública.

Virología; Saneamiento Básico; Enfermedades Transmitidas por el Agua

\section{Colaboradores}

T. Prado e M. P. Miagostovich contribuíram com a concepção e elaboração do estudo. T. Prado escreveu o artigo, e M. P. Miagostovich fez a revisão. Os autores leram e aprovaram o manuscrito final.

\section{Agradecimentos}

À Sabina Victoria Montero (Institut Pasteur de Montevideo) pela revisão do resumo em espanhol. Este trabalho de pesquisa está dentro do escopo das atividades da Fiocruz como centro colaborador da OPAS/OMS em saúde pública e ambiente. 


\section{Referências}

1. Machado CJS. Ciências, políticas públicas e sociedade sustentável. Rio de Janeiro: E-Papers; 2012.

2. Bosch A, Guix S, Sano D, Pintó RM. New tools for the study and direct surveillance of viral pathogens in water. Curr Opin Biotechnol 2008; 19:295-301.

3. Sinclair RG, Jones EL, Gerba CP. Viruses in recreational water-borne disease outbreaks: a review. J Appl Microbiol 2009; 107:1769-80.

4. Okoh AI, Sibanda T, Gusha SS. Inadequately treated wastewater as a source of human enteric viruses in the environment. Review. Int J Environ Res Public Health 2010; 7:2620-37.

5. Heller L, Colosimo EA, Antunes CMF. Environmental sanitation conditions and health impact: a case-control study. Rev Soc Bras Med Trop 2003; 36:41-50.

6. Libânio PAC, Chernicharo CAL, Nascimento NO The water quality dimension: an evaluation of the relationship between social, water availability, water services and public health indicators. Eng Sanit Ambient 2005; 10:219-28.

7. Da Cunha CLN, Ferreira AP, Lopes AGS. Implicações do saneamento na saúde pública observadas na região da Leopoldina, Rio de Janeiro. Rev Baiana Saúde Pública 2007; 31:223-37.

8. Da Paz MGA, Almeida MF, Gunther WMR. Prevalência de diarreia em crianças e condições de saneamento e moradia em áreas periurbanas de Guarulhos, SP. Rev Bras Epidemiol 2012; 15:188-97.

9. Rasella D. Impacto do Programa Água para Todos (PAT) sobre a morbimortalidade por diarreia em crianças do Estado da Bahia, Brasil. Cad Saúde Pública 2013; 29:40-50.

10. Heller L. Basic sanitation in Brazil: lessons from the past, opportunities from the present, challenges for the future. Journal of Comparative Social Welfare 2007; 23:141-53.

11. Instituto Brasileiro de Geografia e Estatística. Pesquisa Nacional de Saneamento Básico - PNSB - 2008. http://www.ibge.gov.br/home/estatis tica/populacao/condicaodevida/pnsb2008/ PNSB_2008.pdf (acessado em 20/Fev/2013).

12. Sistema Nacional de Informações sobre Saneamento. Diagnóstico dos serviços de água e esgotos - 2010. http://www.snis.gov.br/PaginaCarrega. php?EWRErterterTERTer=95 (acessado em 18/ Fev/2013).

13. Vitral CL, Yoshida CFT, Lemos ERS, Teixeira CS, Gaspar AMC. Age-specific prevalence of antibodies to hepatitis A in children and adolescents from Rio de Janeiro, Brazil, 1978 and 1995. Relationship of prevalence to environmental factors. Mem Inst Oswaldo Cruz 1998; 93:1-5.

14. Braga RCC, Valencia LIO, Medronho RD, Escosteguy CC. Estimativa de áreas de risco para hepatite A. Cad Saúde Pública 2008; 24:1743-52.

15. Organização Mundial da Saúde. Diarrhoea: why children are still dying and what can be done. http://www.who.int/maternal_child_adolescent/ documents/9789241598415/en/ (acessado em 14/ Fev/2014).
16. Organização Mundial da Saúde. Country profile of environmental burden of disease. Brazil. http://www.who.int/quantifying_ehimpacts/na tional/countryprofile/brazil.pdf (acessado em 12/ Fev/2014).

17. Instituto Brasileiro de Geografia e Estatística. Pesquisa Nacional por Amostras de Domicílios PNAD. Síntese de Indicadores Sociais. Uma análise das condições de vida da população brasileira. http://www.ibge.gov.br/home/estatistica/popula cao/condicaodevida/indicadoresminimos/sinte seindicsociais2009/indic_sociais2009.pdf (acessado em 20/Fev/2013).

18. Organização Mundial da Saúde. Guidelines for drinking-water quality. http://www.who.int/wa ter_sanitation_health/publications/2011/dwq_ guidelines/en/ (acessado em 10/Fev/2014).

19. Godfree A, Farrell J. Processes for managing pathogens. J Environ Qual 2005; 34:105-13.

20. Fumian TM, Leite JPG, Rose TL, Prado T, Miagostovich MP. One year environmental surveillance of rotavirus specie A (RVA) genotypes in circulation after the introduction of the Rotarix vaccine in Rio de Janeiro, Brazil. Water Res 2011; 45:5755-63.

21. Victoria M, Guimarães FR, Fumian TM, Ferreira FFM, Vieira CB, Shubo T, et al. One year monitoring of norovirus in a sewage treatment plant in Rio de Janeiro, Brazil. J Water Health 2009; 8:158-65.

22. Villar LM, De Paula VS, Diniz-Mendes L, Guimarães FR, Ferreira FFM, Shubo TC, et al. Molecular detection of hepatitis A virus in urban sewage in Rio de Janeiro, Brazil. Lett Appl Microbiol 2007; 45:168-73.

23. Prado T, Silva DM, Guilayn WC, Rose TL, Gaspar AMC, Miagostovich MP. Quantification and molecular characterization of enteric viruses detected in effluents from two hospital wastewater treatment plants. Water Res 2011; 45:1287-97.

24. Fumian TM, Vieira CB, Leite JPG, Miagostovich MP. Assessment of burden of virus agents in urban sewage treatment plant in Rio de Janeiro, Brazil. J Water Health 2013; 11:110-9.

25. Fumian TM, Guimarães FR, Vaz BJP, da Silva MTT, Muylaert FF, Bofill-Mas S, et al. Molecular detection, quantification and characterization of human polyomavirus JC from waste water in Rio de Janeiro, Brazil. J Water Health 2010; 8:438-45.

26. Viancelli A, Garcia LAT, Schiochet M, Kunz A, Steinmetz R, Ciacci-Zanella JR, et al. Culturing and molecular methods to assess the infectivity of porcine circovirus from treated effluent of swine manure. Res Vet Sci 2012; 93:1520-24.

27. Francy DS, Stelzer EA, Bushon RN, Brady AMG, Williston AG, Riddell KR, et al. Comparative effectiveness of membrane bioreactors, conventional secondary treatment, and chlorine and UV disinfection to remove microorganisms from municipal wastewaters. Water Res 2012; 46:4164-78.

28. Zhang K, Farahbakhsh K. Removal of native coliphages and coliform bacteria from municipal wastewater by various wastewater treatment processes: implications to water reuse. Water Res 2007; 41:2816-24. 
29. Li D, Gu AZ, Zeng S-Y, Yang W, He M, Shi H-C. Monitoring and evaluation of infectious rotaviruses in various wastewater effluents and receiving waters revealed correlation and seasonal pattern of occurrences. J Appl Microbiol 2011; 110:1129-37.

30. Tyrrell SA, Rippey SR, Watkins WD. Inactivation of bacterial and viral indicators in secondary sewage effluents, using chlorine and ozone. Water Res 1995; 29:2483-90.

31. Von Sperling M. Introdução à qualidade das águas e ao tratamento de esgotos. v. 1. 3ạ Ed. Belo Horizonte: Universidade Federal de Minas Gerais; 2005.

32. Leite JPG, Carvalho-Costa FA, Linhares AC. Group A rotavirus genotypes and the ongoing Brazilian experience: a review. Mem Inst Oswaldo Cruz 2008; 103:745-53.

33. Centers for Disease Control and Prevention. Progress in the introduction of rotavirus vaccine: Latin America and the Caribbean, 2006-2010. MMWR Morb Mortal Wkly Rep 2011; 60:1611-4.

34. Linhares AC, Stupka JA, Ciapponi A, Bardach AE, Glujovsky D, Aruj PK, et al. Burden and typing of rotavirus group A in Latin America and the Caribbean: systematic review and meta-analysis. Rev Med Virol 2011; 21:89-109.

35. O’Ryan M, Lucero Y, Linhares AC. Rotarix®: vaccine performance 6 years postlicensure. Expert Rev Vaccines 2011; 10:1645-59.

36. Gurgel RQ, Cuevas LE, Vieira SC, Barros VC, Fontes $\mathrm{PB}$, Salustino EF, et al. Predominance of rotavirus $\mathrm{P}[4] \mathrm{G} 2$ in a vaccinated population, Brazil. Emerg Infect Dis 2007; 13:1571-3.

37. Gurgel RQ, Correia JB, Cuevas LE. Effect of rotavirus vaccination on circulating virus strains. Lancet 2008; 371:301-2.

38. Nakagomi T, Cuevas LE, Gurgel RQ, Elrokhsi SH, Belkhir YA, Abugalia M, et al. Apparent extinction of non-G2 rotavirus strains from circulation in Recife, Brazil, after the introduction of rotavirus vaccine. Arch Virol 2008; 153:591-3.

39. Mehnert DU, Stewien KE. Detection and distribution of rotavirus in raw sewage and creeks in São Paulo, Brazil. Appl Environ Microbiol 1993; 59:140-3.

40. Vieira CB, Mendes ACO, Guimarães FR, Fumian TM, Leite JPG, Gaspar AMC, et al. Detection of enteric viruses in recreational waters of an urban lagoon in the city of Rio de Janeiro, Brazil. Mem Inst Oswaldo Cruz 2012; 107:778-84.

41. Ferreira FFM, Guimarães FR, Fumian TM, Victoria M, Vieira CB, Luz S, et al. Environmental dissemination of group A rotavirus: P-type, G-type and subgroup characterization. Water Sci Technol 2009; 60:633-42.

42. Fumian TM, Leite JPG, Castello AA, Gaggero A, Caillou MSL, Miagostovich MP. Detection of rotavirus A in sewage samples using multiplex qPCR and an evaluation of the ultracentrifugation and adsorption-elution methods for virus concentration. JVirol Methods 2010; 170:42-6.

43. Miagostovich MP, Ferreira FFM, Guimarães FR, Fumian TM, Diniz-Mendes L, Luz SLB, et al. Molecular detection and characterization of gastroenteritis viruses occurring naturally in the stream waters of Manaus, Central Amazon, Brazil. Appl Environ Microbiol 2008; 74:375-82.
44. Gabbay YB, Borges AA, Oliveira DS, Linhares AC, Mascarenhas JDP, Barardi CR, et al. Evidence for zoonotic transmission of group $\mathrm{C}$ rotaviruses among chldren in Belém, Brazil. J Med Virol 2008; 80:1666-74

45. Centers for Disease Control and Prevention. Updated norovirus outbreak management and disease prevention guidelines. MMWR Morb Mortal Wkly Rep 2011; 60:1-12.

46. Karst SM. Pathogenesis of noroviruses, emerging RNA viruses. Viruses 2010; 2:748-81.

47. Siebenga JJ, Vennema H, Renckens B, Bruin E, van der Veer B, Siezen RJ, et al. Epochal evolution of GGII.4 norovirus capsid proteins from 1995 to 2006. J Virol 2007; 81:9932-41.

48. Victoria M, Carvalho-Costa FA, Heinemann MB, Leite JP, Miagostovich MP. Prevalence and molecular epidemiology of noroviruses in hospitalized children with acute gastroenteritis in Rio de Janeiro, Brazil, 2004. Pediatr Infect Dis J 2007; 26:602-6.

49. Fioretti JM, Ferreira MSR, Victoria M, Vieira CB, Xavier MPTP, Leite JPG, et al. Genetic diversity of noroviruses in Brazil. Mem Inst Oswaldo Cruz 2011; 106:942-7.

50. Victoria M, Rigotto C, Moresco V, de Abreu Corrêa A, Kolesnikovas C, Leite JPG, et al. Assessment of norovirus contamination in environmental samples from Florianópolis city, Southern Brazil. J Appl Microbiol 2010; 109:231-8.

51. Moresco V, Viancelli A, Nascimento MA, Souza DSM, Ramos APD, Garcia LAT, et al. Microbiological and physicochemical analysis of the coastal waters of southern Brazil. Mar Pollut Bull 2012; 64:40-8.

52. Silva PC, Vitral CL, Barcellos C, Kawa H, Gracie R, Rosa MLG. Hepatite A no Município do Rio de Janeiro, Brasil: padrão epidemiológico e associação das variáveis socioambientais. Vinculando dados do SINAN aos do Censo Demográfico. Cad Saúde Pública 2007; 23:1553-64.

53. De Paula VS, Diniz-Mendes L, Villar LM, Luz SLB, Silva LA, Jesus MS, et al. Hepatitis A virus in environmental water samples from the Amazon Basin. Water Res 2007; 41:1169-76.

54. Barrella KM, Garrafa P, Monezi TA, Hársi CM, Salvi $\mathrm{C}$, Violante PABC, et al. Longitudinal study on occurrence of adenoviruses and hepatitis A virus in raw domestic sewage in the city of Limeira, São Paulo. Braz J Microbiol 2009; 40:102-7.

55. Prado T, Fumian TM, Miagostovich MP, Gaspar AMC. Monitoring the hepatitis A virus in urban wastewater from Rio de Janeiro, Brazil. Trans R Soc Trop Med Hyg 2012; 106:104-9.

56. Vieira CB, Mendes ACO, de Oliveira JM, Gaspar AMC, Leite JPG, Miagostovich MP. Vírus entéricos na Lagoa Rodrigo de Freitas. Oecologia Australis 2012; 16:540-65.

57. Villar LM, De Paula VS, Gaspar AMC. Seasonal variation of hepatitis A virus infection in the city of Rio de Janeiro, Brazil. Rev Inst Med Trop São Paulo 2002; 44:289-92.

58. Rigotto C, Victoria M, Moresco V, Kolesnikovas CK, Corrêa AA, Souza DSM, et al. Assessment of adenovirus, hepatitis A virus and rotavirus presence in environmental samples in Florianopolis, South Brazil. J Appl Microbiol 2010; 109:1979-87. 
59. Sincero TCM, Levin DB, Simões CMO, Barardi CRM. Detection of hepatitis A virus (HAV) in oysters (Crassostrea gigas). Water Res 2006; 40: 895-902.

60. Secretaria de Vigilância em Saúde, Ministério da Saúde. Sistema Nacional de Vigilância em Saúde. Relatório de situação: Amazonas. http://bvsms. saude.gov.br/bvs/publicacoes/relatorio_snvs am_2ed.pdf (acessado em 10/Fev/2014).

61. Russell WC. Adenoviruses: update on structure and function. Review. J Gen Virol 2009; 90:1-20.

62. Schlindwein AD, Rigotto C, Simões MO, Barardi CRM. Detection of enteric viruses in sewage sludge and treated wastewater effluent. Water Sci Technol 2010; 61:537-44.

63. Fongaro G, do Nascimento MA, Rigotto C, Ritterbush G, da Silva AD'A, Esteves PA, et al. Evaluation and molecular characterization of human adenovirus in drinking water supplies: viral integrity and viability assays. Virol J 2013; 10:166.

64. Bofill-Mas S, Albinana-Gimenez N, ClementeCasares P, Hundesa A, Rodriguez-Manzano J, Allard A, et al. Quantification and stability of human adenoviruses and polyomavirus JCPyV in wastewater matrices. Appl Environ Microbiol 2006; 72:7894-96.

65. Albinana-Gimenez N, Miagostovich MP, Calgua B, Huguet JM, Matia L, Girones R. Analysis of adenoviruses and polyomaviruses quantified by qPCR as indicators of water quality in source and drinkingwater treatment plants. Water Res 2009; 43:2011-9.

66. Prado T, Guilayn WCPB, Gaspar AMC, Miagostovich MP. The efficiency of concentration methods used to detect enteric viruses in anaerobically digested sludge. Mem Inst Oswaldo Cruz 2013; 108:77-83.

67. Payment P, Locas A. Pathogens in water: value and limits of correlation with microbial indicators. Ground Water 2011; 49:4-11.

68. Da Costa EV. Perfil genômico dos poliovírus de origem vacinal isolados de casos de paralisias flácidas agudas, no Brasil, no período pós-eliminação dos poliovírus selvagens da região das Américas [Tese de Doutorado]. Rio de Janeiro: Instituto Oswaldo Cruz, Fundação Oswaldo Cruz; 2011.

69. Gregio CRV. Caracterização genômica de poliovírus derivado da vacina isolados a partir de amostras ambientais [Tese de Doutorado]. Rio de Janeiro: Instituto Nacional de Controle de Qualidade em Saúde, Fundação Oswaldo Cruz; 2006.

70. Hachich EM, Galvani AT, Padula JA, Stoppe NC, Garcia SC, Bonanno VMS, et al. Pathogenic parasites and enteroviruses in wastewater: support for a regulation on water reuse. Water Sci Technol 2013; 67:1512-8.

71. Pereira JSO. Vigilância ambiental de poliovírus em apoio às atividades de erradicação global da poliomielite [Dissertação de Mestrado]. Rio de Janeiro: Instituto Nacional de Controle de Qualidade em Saúde, Fundação Oswaldo Cruz; 2013.
72. Calgua B, Fumian T, Rusinõl M, Rodriguez-Manzano J, Mbayed VA, Bofill-Mas S, et al. Detection and quantification of classic and emerging viruses by slimmed-milk flocculation and PCR in river water from two geographical areas. Water Res 2013; 47:2797-810.

73. Mendes-Diniz L, de Paula VS, Luz SLB, Niel C. High prevalence of human Torque teno virus in streams crossing the city of Manaus, Brazilian Amazon. J Appl Microbiol 2008; 105:51-8.

74. Dos Santos DRL, De Paula VS, Oliveira JM, Marchevsky RS, Pinto MA. Hepatitis E virus in swine and effluent samples from slaughterhouses in Brazil. Vet Microbiol 2010; 149:236-41.

75. Pavio N, Meng X-J, Renou C. Zoonotic hepatitis E: animal reservoirs and emerging risks. Vet Res 2010; $41: 46$

76. Homma A, Schatzmayr HG. Quantitative method of viral pollution determination for large volume of water using ferric hydroxide gel impregnated on the surface of glassfibre cartridge filter. Mem Inst Oswaldo Cruz 1974; 72:31-41.

77. Sutmoller F, Gaspar AMC, Cynamon SE, Richa N, Mercadante LAC, Schatzmayr HG. A water-borne hepatitis A outbreak in Rio de Janeiro. Mem Inst Oswaldo Cruz 1982; 77:9-17.

78. Girones R, Ferrús MA, Alonso JL, Rodriguez-Manzano J, Calgua B, Corrêa AB, et al. Molecular detection of pathogens in water: the pros and cons of molecular techniques. Water Res 2010; 44:4325-39.

79. Rajal VB, McSwain BS, Thompson DE, Leutenegger CM, Kildare BJ, Wuertz S. Validation of hollow fiber ultrafiltration and real-time PCR using bacteriophage PP7 as surrogate for the quantification of viruses from water samples. Water Res 2007; 41:1411-22.

80. Rodriguez RA, Pepper IL, Gerba CP. Application of PCR-based methods to assess the infectivity of enteric viruses in environmental samples - Minireview. Appl Environ Microbiol 2009; 75:297-307.

81. Ministério da Saúde. Portaria no 2.914, de 12 de dezembro de 2011. Dispõe sobre os procedimentos de controle e de vigilância da qualidade da água para consumo humano e seu padrão de potabilidade. Diário Oficial da União 2011; 14 dez.

82. Conselho Nacional do Meio Ambiente. Resolução no 357, de 17 de março de 2005. Dispõe sobre a classificação dos corpos de água e diretrizes ambientais para o seu enquadramento bem como estabelece as condições e padrões de lançamento de efluentes e dá outras providências. Diário Oficial da União 2011; 18 mar

83. Conselho Nacional do Meio Ambiente. Resolução no 430 , de 13 de maio de 2011. Dispõe sobre as condições e padrões de lançamento de efluentes, complementa e altera a Resolução 357, de 17 de março de 2005, do Conselho Nacional do Meio Ambiente. Diário Oficial da União 2011; 16 mai.

Submetido em 31/Mar/2013

Versão final reapresentada em 19/Fev/2014

Aprovado em 27/Mar/2014 